ARCHITECTURAL DIAGRAMS AND DESIGN STRATEGIES: REFLECTIONS ON COMPOSITION AND RHETORIC.

\title{
SOBREIRA, FABIANO
}

Arquiteto e Urbanista, Doutor em Desenvolvimento Urbano, Professor do Curso de Arquitetura e Urbanismo do UniCEUB, Arquiteto do Departamento Técnico da Câmara dos Deputados.fabiano@mgs.arq.br

\section{GUIMARÃES, ADRIANA}

Estudante do Curso de Arquitetura e Urbanismo do UniCEUB, adrianadrikete24@gmail.com

\section{SIEBEL, AMANDA}

Estudante do Curso de Arquitetura e Urbanismo do UniCEUB, arq.amandaseibel@gmail.com

\begin{abstract}
RESUMO
Este artigo tem como objetivo apresentar reflexões preliminares sobre o uso de recursos diagramáticos na arquitetura contemporânea, a partir de duas abordagens complementares: (1) retórica propositiva e (2) análise da composição. A primeira questão está relacionada ao uso de recursos gráficos diagramáticos como estratégia de apresentação, enquanto a segunda aborda a síntese analítica das estratégias de composição no projeto. Considerando que proposição e análise são dois exercícios complementares e necessários ao projeto e que se retroalimentam constantemente (como o diálogo permanente e necessário entre prática, ensino e pesquisa), propomos uma reflexão preliminar sobre o papel do exercício de síntese gráfica e textual (o diagrama) e seu impacto na Arquitetura Contemporânea. Metodologicamente, foram estudados projetos em situação de concurso (em particular, o Concurso Internacional para o Museu Guggenheim de Hensinki), por se tratarem de eventos que, por sua natureza, são exercícios de síntese propositiva e analítica, em que a retórica diagramática exerce papel fundamental no projeto e no julgamento qualitativo.
\end{abstract}

PALAVRAS-CHAVE: projeto, diagramas, composição, retórica, concursos.

\begin{abstract}
This paper presents preliminary reflections on the use of diagrammatic resources on contemporary architecture, from two complementary perspectives: (1) proposal rhetoric and (2) composition analysis. The first approach is related to the use of diagrammatic graphic resources as presentation strategies, while the second approach presents analytical synthesis on design composition strategies. Considering that proposition and analysis are two complementary actions, necessary to design, and that continuously feed each other (as the permanent and necessary dialogue between practice, teaching and research), one proposes discussions on the role of the graphic and textual synthesis (the diagram) and its impact on contemporary Architecture. Methodologically, winning competition designs were studied (in particular, the International Competition for the Guggenheim Museum in Helsinki), considering competitions as event marked by a constant exercise of analytical and proposal synthesis, where diagrammatic rhetoric play an important role on design and qualitative judgement.
\end{abstract}

KEY-WORDS: architectural design, diagrams, composition, rhetoric, competitions.

\section{DIAGRAMAS: REFLEXÕES CONTEMPORÂNEAS}

De acordo com Montaner (2014), a utilização do diagrama, enquanto "instrumento abstrato, complexo e versátil" se destaca como um dos quatro processos peculiares da arquitetura produzida entre meados dos anos 1990 e o início do século XXI.

Alguns dos principais arquitetos contemporâneos (reconhecidos duplamente por sua produção arquitetônica e intelectual) também destacam o uso desse recurso como uma característica de uma nova forma de pensar. Rem Koolhass (escritório OMA), um dos precursores e inovadores na utilização do instrumento, vê o diagrama não apenas como um elemento criativo para construir, "mas também como um modo de olhar. (...) olhamos para os edifícios do mesmo modo diagramático". (KOOLHAAS, em STEELE, 2013).

Segundo Moneo (2008), se por um lado Le Corbusier difundiu bastante o pensamento arquitetônico em torno da ideia de "planta livre", Rem Koolhaas incorporou à cultura arquitetônica do final do século XX e início do XXI o conceito de "corte livre". Esse novo olhar é construído e expresso muitas vezes de 
forma diagramática e conceitual, mais do que por meio de perspectivas e imagens tridimensionais realistas ou elementos gráficos técnicos usuais. Ainda segundo Koolhaas:

Para nós, o diagrama não é apenas mais um dispositivo que desencadeia a arquitetura, ou que nos permite desencadear a arquitetura. É também um dispositivo por meio do qual olhamos o mundo e tentamos representar algumas das condições bizarras que observamos. Para mim, isso permanece como parte importante do que podemos chamar de o "diagrama" hoje (STEELE, 2013, p. 29).

As estratégias diagramáticas do OMA vão além dos recursos tradicionais, de representações bidimensionais, ao combinar os esquemas topológicos aos elementos tridimensionais e fotografias (Figura 01).

Figura 1 - Estratégias diagramáticas do OMA/Rem Koolhaas em concursos de arquitetura. Acima: Museu de Belas Artes do Québec. Abaixo: Casa de Música do Porto.
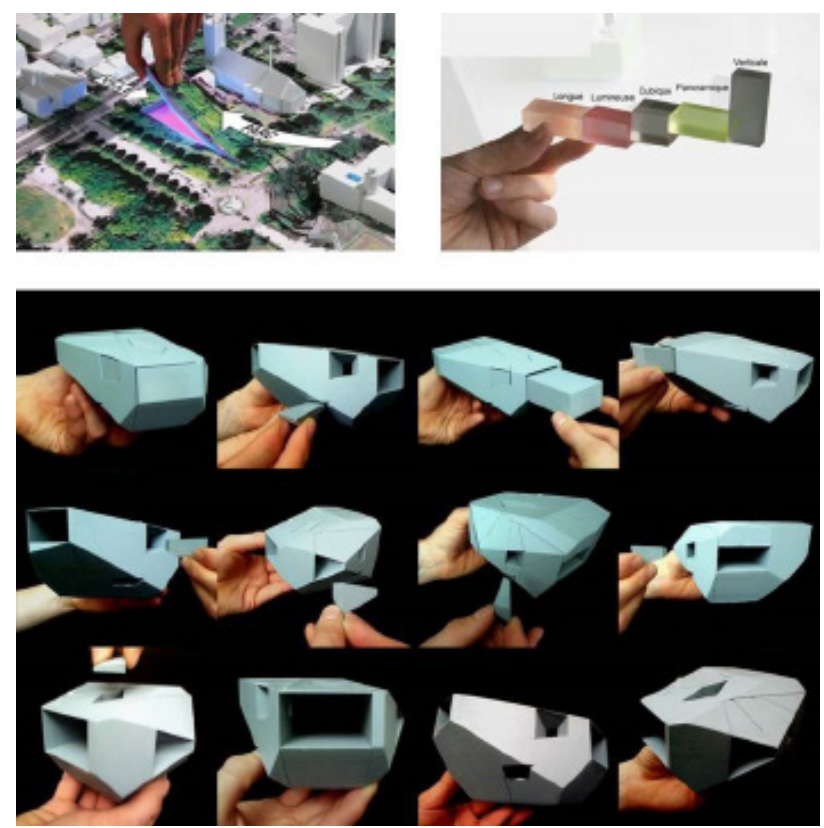

Fonte: concursosdeprojeto.org

Outro arquiteto conhecido pelas reflexões e práticas em torno do diagrama é Peter Eisenman (IZAR, 2015). Sobre o uso do diagrama no exercício projetual, o arquiteto afirma:

Uso o diagrama não como forma, mas como ideia. Tento encontrar algo que funcione como diagrama para gerar algo a partir das condições que não poderia ter previsto anteriormente. O diagrama é diferente em cada caso. A mudança, ou o uso, da concepção do diagrama tem evoluído de diagramas mais simples até outros mais complexos." (EISENMAN, em GALOFARO, 1999, p.47).

Segundo Adamczyk (2015), os desenhos em arquitetura (e nesse contexto podemos inserir os diagramas) podem ser cada vez mais interpretados não apenas como expressões de uma ideia mas como parte do processo de desenvolvimento reflexivo e da imaginação.

O diagrama, enfim, é associado à captura de dados por meio do observador de maneira mais ágil, configurando-se como um recurso sintetizador de raciocínio, por meio de instrumentos iconográficos (GARCIA, 2010). O diagrama se posiciona, portanto, entre o processo e o produto do projeto, como um discurso visual, muitas vezes sem tipologias definidas. Neste artigo consideramos como recurso diagramático não apenas a representação topológica clássica (bi ou tridimensional), amplamente utilizada na descrição de sistemas e processos. Consideramos uma abordagem mais ampla, em que a maquete física, a fotografia, o croqui, as perspectivas e fotomontagens podem ser interpretados como recursos diagramáticos (Figura 1), desde que seu propósito seja a comunicação sintética (e não realista, nem unicamente técnica) de uma ideia.

\section{CONCURSOS: RETÓRICA E SÍNTESE DIAGRAMÁTICA}

De acordo com o conceito de "Arquitetura Potencial" (ADAMCZYK et al, 2004; CHUPIN, 2010; 2015), os concursos de projeto, mais do que processos competitivos para a escolha da melhor solução para um problema específico, são também campos de especulação criativa e de formação profissional, assim como espaços de debates sobre a produção e a gestão do ambiente construído. Nesse sentido, o projeto de arquitetura em situação de concurso é aqui interpretado ao mesmo tempo como um instrumento propositivo e reflexivo para a disciplina, para a profissão e para a gestão pública (SOBREIRA, 2015).

O concurso, como instrumento analítico, devido ao amplo repertório propositivo, permite observar diversas estratégias de composição simultâneas, sobre um objeto e um mesmo contexto, o que permite fixar variáveis e aprofundar o processo analítico e comparativo: diferentes expressões e respostas simultâneas a um mesmo problema.

Chupin (2002) situa os projetos de concurso exatamente no ponto de convergência entre a disciplina e a profissão, uma vez que há uma relação de ação, que está vinculada à prática de projeto com a cognição, relativa às trocas de críticas e julgamentos internos e externos.

Segundo Boutinet (1990), por exemplo, uma das particularidades do conceito de projeto éa existência 
de duas ordens: "a ordem do discurso, encarregado de explicitar, de prescrever e de planejar; e a "ordem da ação, na qual as intenções se convertem em prática". Talvez por essa razão, observa-se que a dinâmica de apropriação dos conceitos no discurso arquitetônico oferece aos pesquisadores um vasto e rico campo de especulação teórica e de análises em torno do processo de projeto. Destacamos, nesse sentido, a reflexão de Tostrup (1999), que sugere:

...por trás da superficialidade dos 'slogans', a relação entre a arquitetura e o discurso que é escrito é surpreendentemente vaga. Ainda assim, a linguagem que acompanha os projetos oferece pistas interessantes sobre o raciocínio por trás do ato projetual e sobre outros fatores que não são expressos no discurso, mas que estão implícitos. (TOSTRUP, 1999, p.9)

No caso dos concursos, considerando que em geral não há o diálogo direto entre o arquiteto e o cliente, as pranchas precisam expressar a retórica não apenas do edifício ou do espaço proposto, como também das ideias levadas em consideração durante o processo projetual. Como consequência, nos projetos em situação de concurso, as estratégias são reveladas, além dos desenhos técnicos e perspectivas, de maneira diagramática e textual.

\section{CONCURSO PARA O MUSEU GUGGENHEIM DE HELSINKI}

Em junho de 2014 a Fundação Guggenheim lançou o concurso internacional aberto, em duas etapas, para selecionar a melhor proposta para o Museu Guggenheim de Hensilki, na Finlândia, com enfoque em expressões de arte dos séculos XX e XXI. Foram submetidas 1.715 propostas para a primeira etapa, das quais foram selecionados oito projetos finalistas. O projeto vencedor é de autoria do escritório Moreau Kusunoki Architectes, sediado em Paris.

De acordo com as bases do concurso, os projetos foram analisados a partir de cinco critérios: relação com a paisagem da cidade, arquitetura, funcionalidade, sustentabilidade e viabilidade construtiva. Mais especificamente, esperava-se das propostas, segundo as bases do concurso, as seguintes qualidades: originalidade do projeto, potencial para se tornar um ícone e um símbolo para Helsinki; sensibilidade em relação ao contexto histórico do lugar (região portuária); sustentabilidade (perspectivas econômica, social e ambiental); forte conexão com o centro histórico, o porto e o contexto urbano; adequação ao ideal Nórdico, incluindo os princípios de Abertura/ Integração e Acessibilidade.
O local de implantação (área de aproximadamente 18.520 m2), na região portuária, é considerado como um portal de entrada para a cidade a partir do mar e diretamente conectado ao centro histórico. A intenção é que o Museu, além de espaço de cultura e arte, possa se consolidar como espaço cívico para a população local e os visitantes.

Figura 2 - Área central e região portuária de Helsinki, com a demarcação do local de construção do Museu Guggenheim.

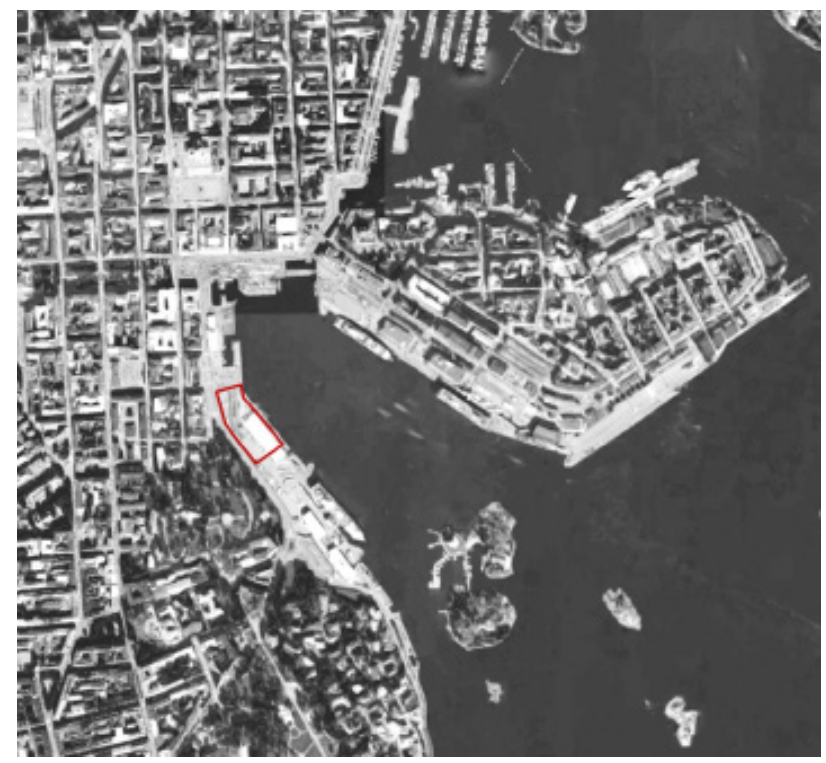

Fonte: autor, editado a partir do Google Maps Helsinki Guggenheim Museum International Competition, 2014

A construção foi estimada em 130 milhões de Euros e a área construída de aproximadamente 12.000 m2 (dos quais cerca de 4.000 m2 dedicados a áreas de exposição). Ainda de acordo com as bases do concurso, os projetos deveriam privilegiar a interação social e as possibilidades de experimentação da arte. O programa, além dos espaços expositivos, incluiu salas de aula, auditório flexível, café/bar, restaurante, área administrativa, armazenamento, lojas e instalações diversas. Deveriam também ser previstos espaços expositivos em áreas abertas. No que se refere à materialidade foram apresentadas referências especiais ao uso criativo da madeira, à tradição construtiva Finlandesa, além das mais avançadas tecnologias digitais. O processo entre o lançamento do concurso e a decisão final durou doze meses (resultado final em Junho de 2015).

O Júri foi composto por onze membros, dos quais sete arquitetos (representantes de escritórios locais e internacionais, universidades e técnicos da Prefeitura de Helsinki) e quatro representantes de instituições locais e internacionais, com formações diversas: Fundação Guggenheim; Centro de Pesquisa Técnica da Finlândia; Prefeitura de Helsinki e Ministério do 
Meio Ambiente da Finlândia. Trata-se, portanto, de júri híbrido entre arquitetos e não-arquitetos, tanto do contexto local como internacional. Antes do encontro presencial para a anállise da primeira fase, que durou 4 dias, os 1.715 trabalhos foram disponibilizados em meio eletrônico, a fim de que os membros do júri pudessem realizar análises prévias. Uma comissão técnica realizou uma análise preliminar dos trabalhos, para verificação de atendimento às diretrizes das bases do concurso. Todos os trabalhos, mesmo aqueles indicados como "desclassificáveis" pela referida comissão, foram avaliados pelo Júri. Recomendação especial foi dada ao Júri para considerar o conceito subjacente a cada proposta, sua contribuição à ideia contemporânea de museu e sua relação com o tecido urbano da cidade. A seguir, apresentamos breve análise sobre a abordagem retórica/diagramática de cada uma das seis propostas finalistas, além de comentários do júri sobre os projetos. De acordo com a Ata do Júri, os finalistas se diferenciam uns dos outros tanto no que se refere ao desenvolvimento programático quanto à forma, mas têm em comum o potencial reflexivo sobre questões consideradas centrais para o concurso: "o que é um museu no contexto atual ?"; "De que forma esse novo museu pode proporcionar dinâmicas sociais e intelectuais que sejam vitais para a cidade?"

\section{Art in the City}

O Júri destacou esta proposta pelo agrupamento de pavilhões, que se apresentam como uma continuidade do tecido urbano e de elementos arquitetônicos existentes. A iluminação natural da proposta foi ressaltada (apesar de ressalvas sobre o formato da cobertura). Em resumo, um dos principais méritos do projeto, segundo o Júri, foi o potencial de redefinir o museu como uma experiência urbana, e não apenas arquitetônica. No que se refere às estratégias diagramáticas e à retórica gráfica, destacamos a originalidade da primeira prancha do projeto, que apresenta uma perspectiva aérea do museu inserido em paisagem que inclui a área portuária e o centro da cidade, em padrão gráfico que se assemelha a uma "história em quadrinhos", em que o realismo usual - cada vez mais comum nos concursos - foi substituído pelo caráter lúdico e dinâmico das ilustrações que parecem ter sido feitas à mão livre. Nessa imagem o projeto do museu é apenas mais um elemento na paisagem, repleta de personagens e situações de interação e ocupação do espaço público, o que sugere (sem necessidade de textos) a ideia de inserção urbana e apropriação coletiva do projeto no contexto.

Na quarta prancha a estratégia se repete, desta vez na escala do edifício, em uma perspectiva (que também tem expressão lúdica e que parece ser feita à mão livre) em que o uso dos espaços se destaca, e não a materialidade, nem a plástica do edifício. A imagem é preenchida por diversos personagens, em situações diversas, que se espalham ao longo dos pavilhões e espaços intersticiais. Na mesma prancha, vale destacar um diagrama técnico, que procura sintetizar as estratégias ambientais e bioclimáticas. Também como recurso visual foram apresentadas imagens de florestas típicas da Finlândia e texturas das madeiras, em evidente referência à demanda das bases do concurso, de utilização desse material no projeto. Percebe-se que as principais diretrizes do concurso (contexto urbano, sustentabilidade, uso da madeira) foram objetos de ilustração sintética, por meio de recursos diagramáticos (desenhos, esquemas e fotos).

Figura 3 - Concurso - Museu Guggenheim Helsinki. Projeto Finalista: "Art in the City". Prancha 01.

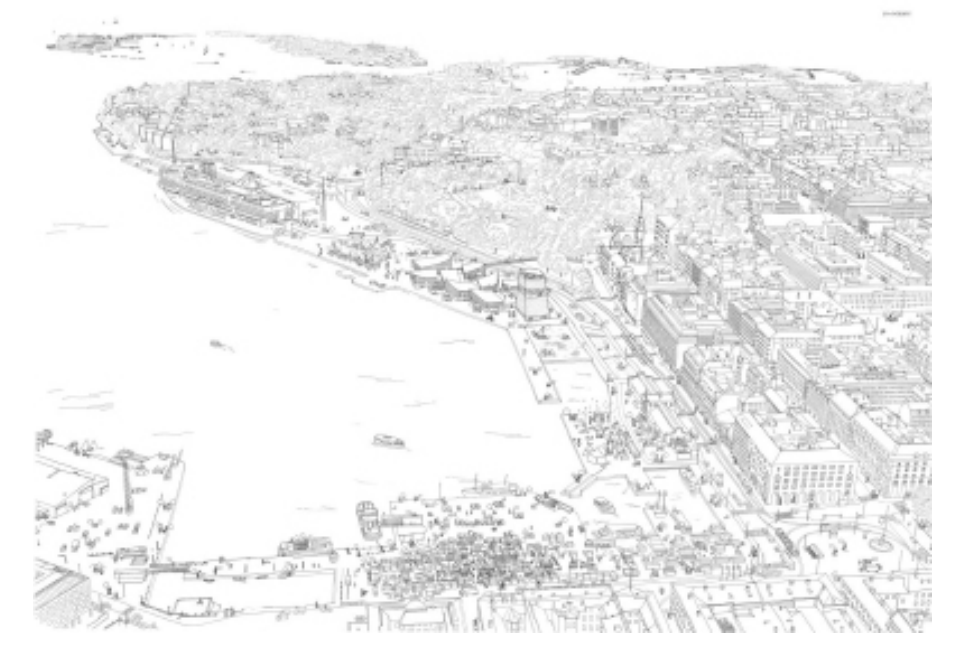

Fonte: concursosdeprojeto.org. Disponível em: http://www.concursosdeprojeto.org/2014/12/06 finalistas-museu-guggenheim 
Figura 4 - Concurso - Museu Guggenheim Helsinki. Projeto Finalista: "Art in the City". Prancha 04.
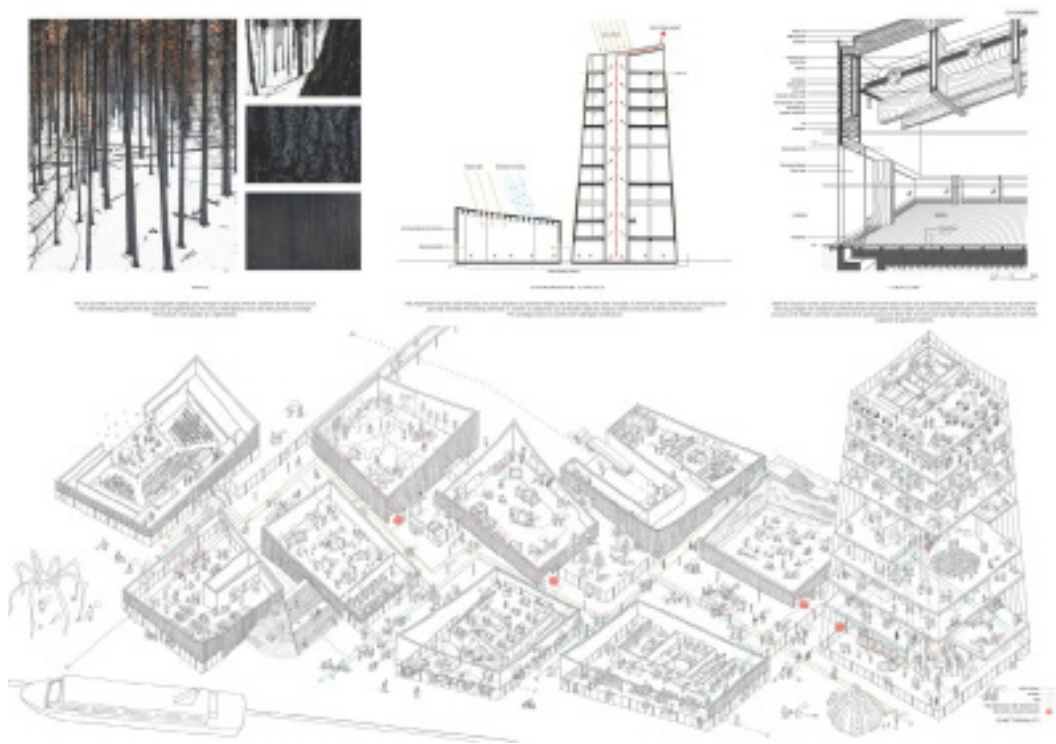

Fonte: concursosdeprojeto.org. Disponível em: http://www.concursosdeprojeto.org/2014/12/06/finalistas-museu-guggenheim

\section{Two-in-one Museum}

O Júri destacou, nesta proposta, o aspecto industrial e vernacular da volumetria e a flexibilidade dos espaços internos. A separação entre atividades de uso público (localizadas no térreo) eas áreas de exposição (pavimento superior) também foi um elemento ressaltado pelos avaliadores. A silhueta ao mesmo tempo discreta e original do edifício foi também destacada.

A primeira prancha do projeto apresenta uma série de recursos diagramático-conceituais, com destaque para o título da prancha e a imagem utilizada como analogia: "Ceci n'est pas un Musée" (Isto não é um Museu), em referência direta à conhecida obra do artista plástico Belga, Rene Magritte, intitulada "La
Trahison desimages", criadaem 1948. Uma reprodução da referida obra é inserida na prancha: uma ilustração de um cachimbo e a inscrição "Ceci n' est pas une pipe" (Isto não é um cachimbo). Na mesma prancha são inseridos diagramas de implantação, que buscam contextualizar o museu com seu entorno.

A última prancha reúne outros recursos diagramáticos, associados às questões técnicas, ambientais e programáticas da proposta, além da volumetria. Neste último caso, utilizando a fotografia como recurso retórico-diagramático (uma mão que manipula o volume), recurso recorrente em obras contemporâneas, como o escritório OMA, reconhecido pela utilização de recursos diagramáticos/fotográficos em suas obras, como vimos na parte inicial deste artigo.

Figura 05 - Concurso - Museu Guggenheim Helsinki. Projeto Finalista: “Two in One Museum”. Prancha 01.

\section{CECI N'EST PAS UN MUSÉE}

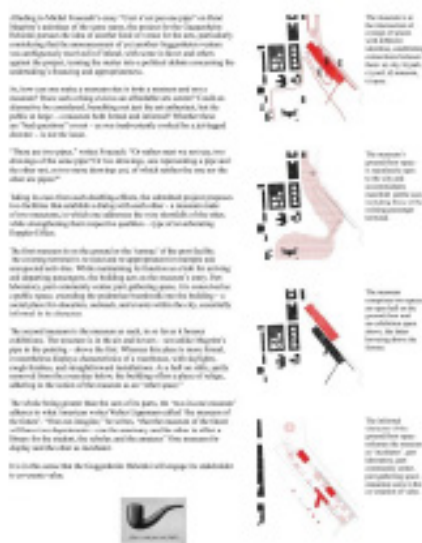

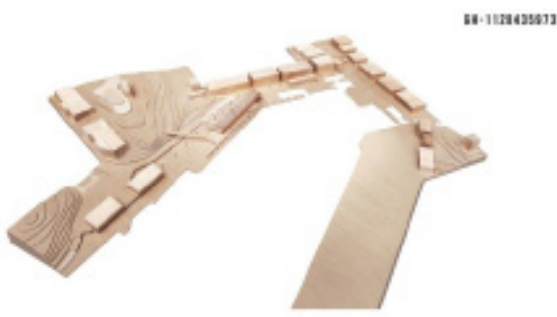

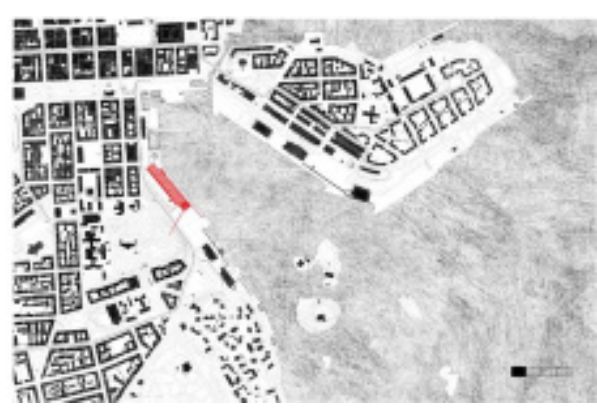

Fonte: concursosdeprojeto.org. Disponível em: http://www.concursosdeprojeto.org/2014/12/06/finalistas-museu-guggenheim 
Figura 06 - Concurso - Museu Guggenheim Helsinki. Projeto Finalista: “Two in One Museum”. Prancha 04.

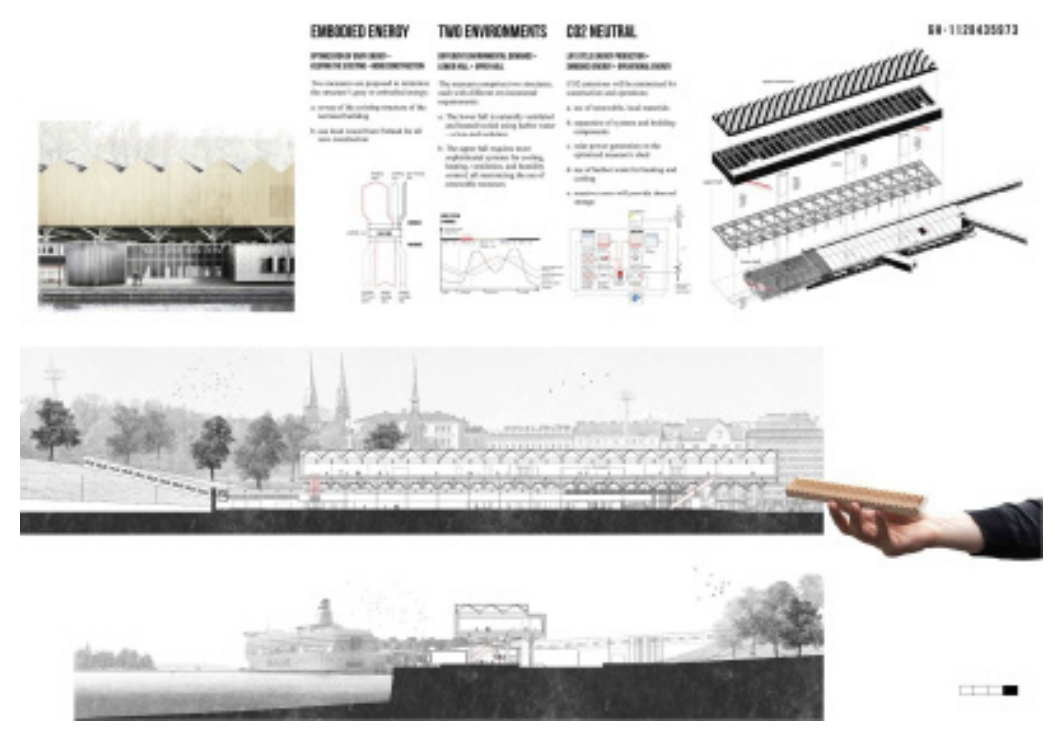

Disponível em: http://www.concursosdeprojeto.org/2014/12/06/finalistas-museu-guggenheim

\section{Quiet Animal}

A integração entre imagem e tecnologia é um dos destaques deste projeto, que se mostrou, segundo o Júri, ao mesmo tempo simples e extraordinário. Apesar das qualidades associadas ao destaque visual da proposta, houve ressalvas em relação à lógica programática, que carecia de desenvolvimento. Um dos elementos ressaltados pelo Júri é a utilização de elementos estéticos como recursos de energia sustentável, apesar de reservas em relação ao sistema construtivo.

No que se refere aos recursos gráficos, destaca-se na primeira prancha (figura 07) a sequência de diagramas que ilustram a inserção do projeto na malha urbana sob várias perspectivas (espaço público, acesso, malha urbana, referências arquitetônicas, etc). O título do trabalho, conforme sugerido pelos autores, é uma analogia aos blocos/quadras que marcavam a paisagem urbana de Helsinki no século XVII, conhecidos como "wild animals". Visual e conceitualmente, o principal elemento da proposta é uma segunda pele, ondulada, que tem ao mesmo tempo função visual e de conforto ambiental.

Na prancha 4 (figura 08) destacam-se diagramas de sustentabilidade (abordada sob a perspectiva social, ambiental e econômica), de eficiência energética e conforto ambiental.

Figura 07 - Concurso - Museu Guggenheim Helsinki. Projeto Finalista: “Quiet Animal”. Prancha 01.

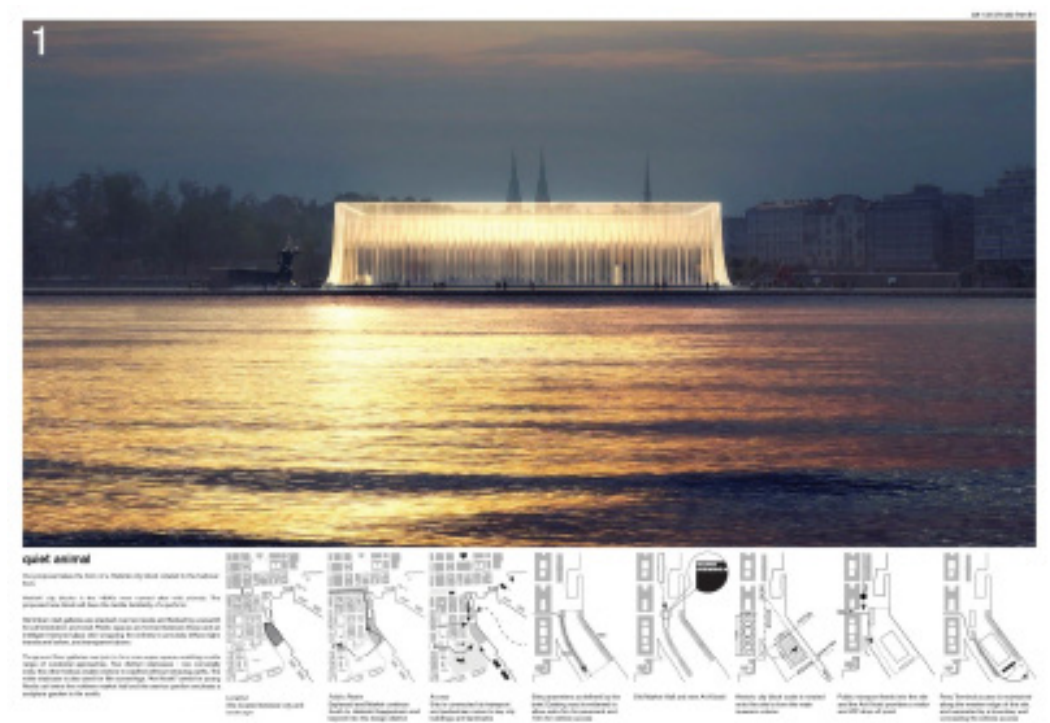

Fonte: concursosdeprojeto.org. Disponível em: http://www.concursosdeprojeto.org/2014/12/06/finalistas-museu-guggenheim 
Figura 08 - Concurso - Museu Guggenheim Helsinki. Projeto Finalista: “Quiet Animal”. Prancha 04.

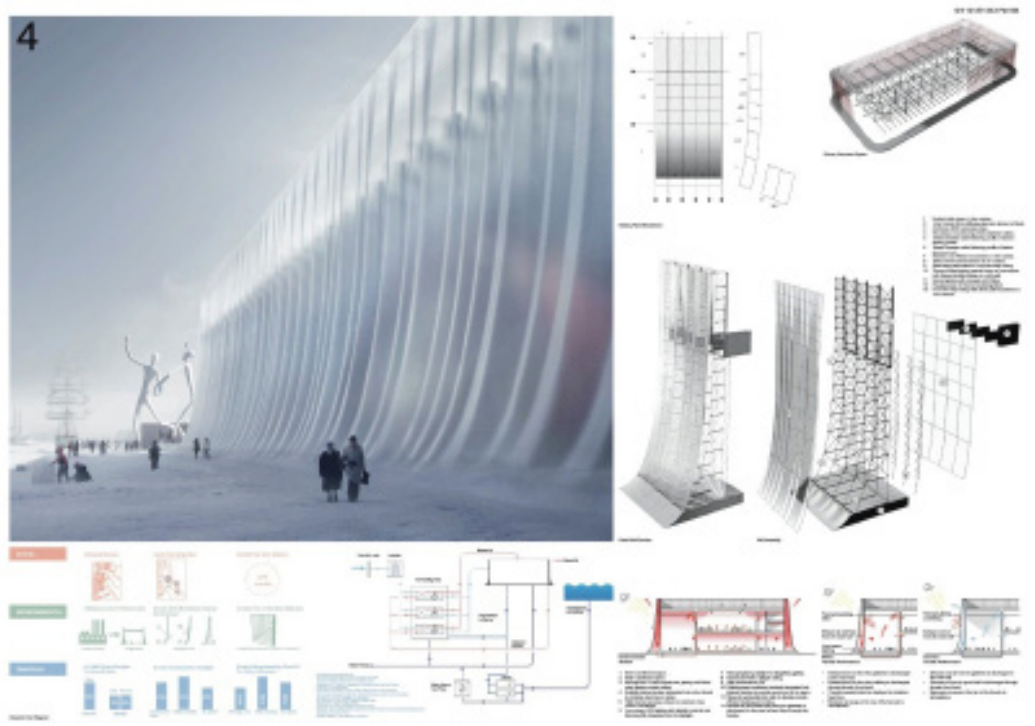

Fonte: concursosdeprojeto.org. Disponível em: http://www.concursosdeprojeto.org/2014/12/06/finalistas-museu-guggenheim

\section{Rooms}

Relação com a paisagem da cidade e o entorno e utilização de materiais de edificações existentes foram algumas das qualidades destacadas pelo Júri para esta proposta (47 Rooms), que utilizou como referência os armazéns do porto de Helsinki e a importância da rede de espaços internos que propiciam o que os autores denominam de "vida pública interior", devido às condições climáticas extremas enfrentadas pela cidade.

O projeto parte das condições climáticas como base conceitual da proposta e defende a ideia do museu como uma atmosfera ativa que se vivencia em seu interior e não como um objeto passivo ou ícone arquitetônico, que se observa à distância. As pranchas 2 e 3 (figura 09) expressam, de forma diagramática, tal relação entre o conceito arquitetônico e as condições climáticas dos espaços internos.

A prancha 4 (figura 10) se utiliza de ilustrações mais abstratas, como recurso conceitual de expressão da diversidade de atmosferas espaciais. As imagens parecem fazer analogia a obras de artes plásticas, com expressão gráfica mais conceitual e menos arquitetônica.

Figura 09 - Concurso - Museu Guggenheim Helsinki. Projeto Finalista: "47 Rooms". Pranchas 02 (esquerda) e 03 (direita).
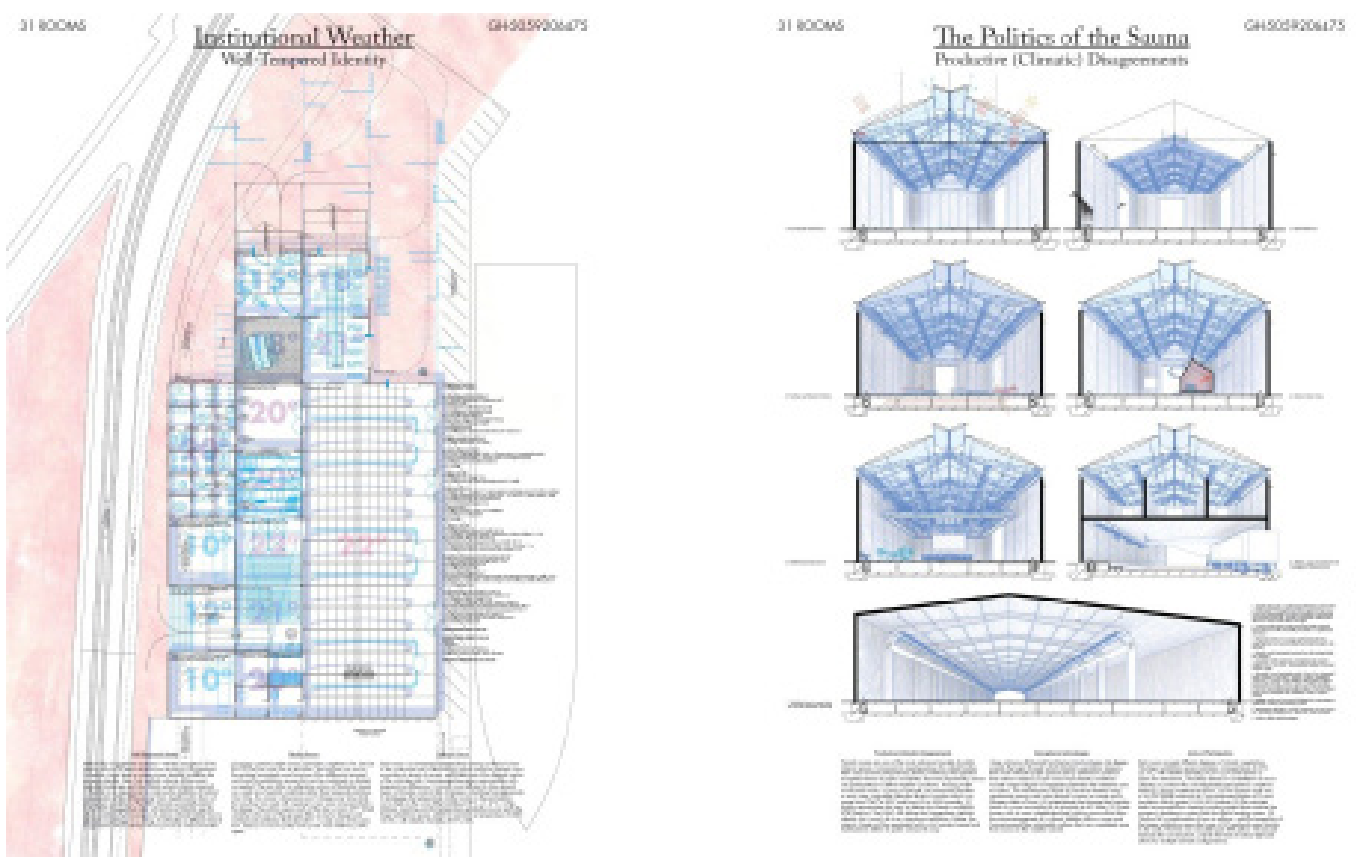

Fonte: concursosdeprojeto.org. Disponível em: http://www.concursosdeprojeto.org/2014/12/06/finalistas-museu-guggenheim 
Figura 10 - Concurso - Museu Guggenheim Helsinki. Projeto Finalista: "47 Rooms”. Prancha 04 (esquerda) e detalhe da prancha (direita).

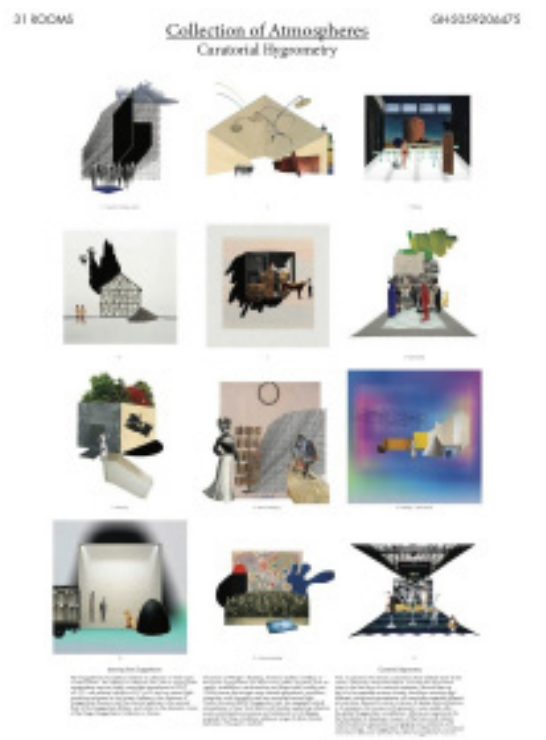

Curatorial Hygrometry
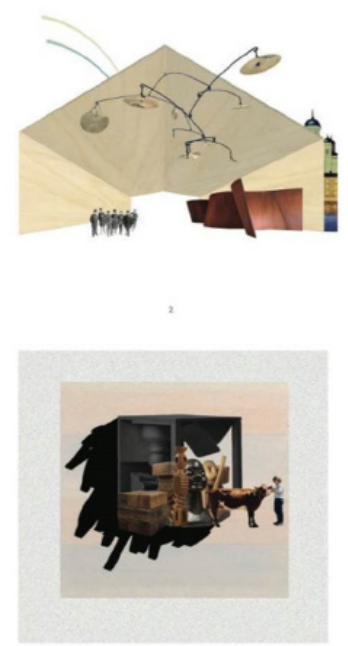

Fonte: concursosdeprojeto.org. Disponível em: http://www.concursosdeprojeto.org/2014/12/06/finalistas-museu-guggenheim

\section{Guggenheim Commons}

O Júri destacou, neste trabalho, a compreensão do funcionamento da cidade e as pesquisas relacionadas ao conceito contemporâneo de museu, tanto no que se refere ao funcionamento interno quanto sua relação com o tecido urbano. Atenção especial foi dada ao espaço público e ao potencial das áreas expositivas.

Este projeto se destaca, entre os demais, pela ampla utilização de recursos diagramáticos analíticos e não apenas propositivos. A prancha 01 (figura 11) apresenta um diagnóstico diagramático sobre o funcionamento da região portuária e sua relação com o centro histórico, identificando barreiras e equipamentos públicos. Nesse sentido, a abordagem se assemelha à estratégia do projeto finalista "Art in the City", em que a proposta do museu parte de uma reflexão sobre a cidade e seu funcionamento (de fora pra dentro).

Na prancha 02 (figura 12) a conceituação básica da proposta é ilustrada, de forma diagramática, com exemplos de outros museus, evidenciando a importância dos espaços livres (extras) em relação aos espaços dedicados a funções específicas (exposição, administração, etc). Um dos principais argumentos da proposta são os espaços livres, como uma oferta do Museu para a cidade, para além de suas funções expositivas. Tais qualidades são também apresentadas na prancha 03 (figura 13), quando os espaços livres, o programa, os fluxos, a relação com a cidade, a iluminação, entre outros tópicos, são apresentados em diagramas.

Figura 11 - Concurso - Museu Guggenheim Helsinki. Projeto Finalista: “Guggenheim Commons". Prancha 01.

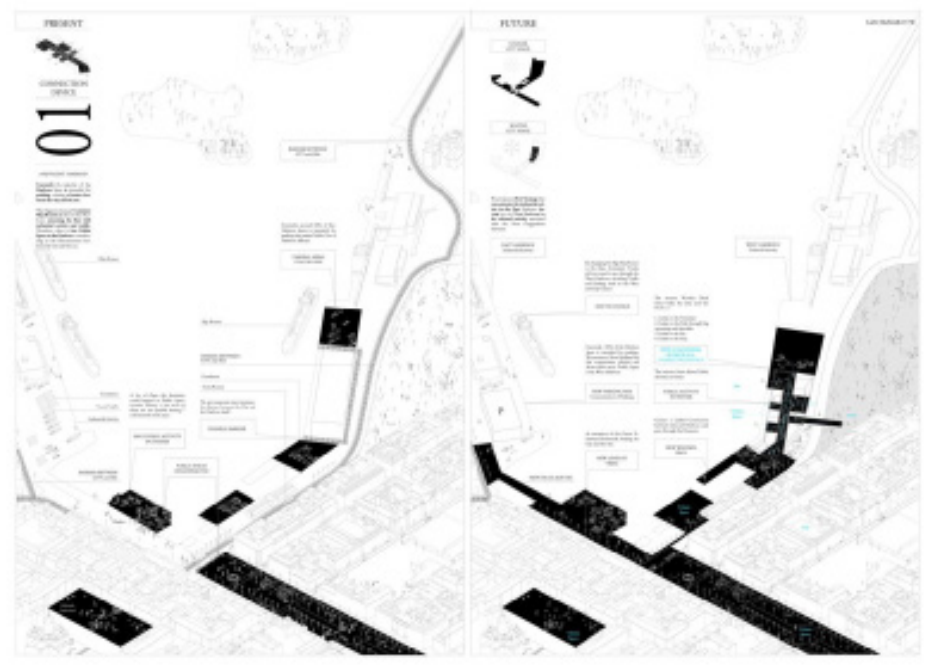

Fonte: concursosdeprojeto.org. Disponível em: http://www.concursosdeprojeto.org/2014/12/06/finalistas-museu-guggenheim 
Figura 12 - Concurso - Museu Guggenheim Helsinki. Projeto Finalista: "Guggenheim Commons". Prancha 02.

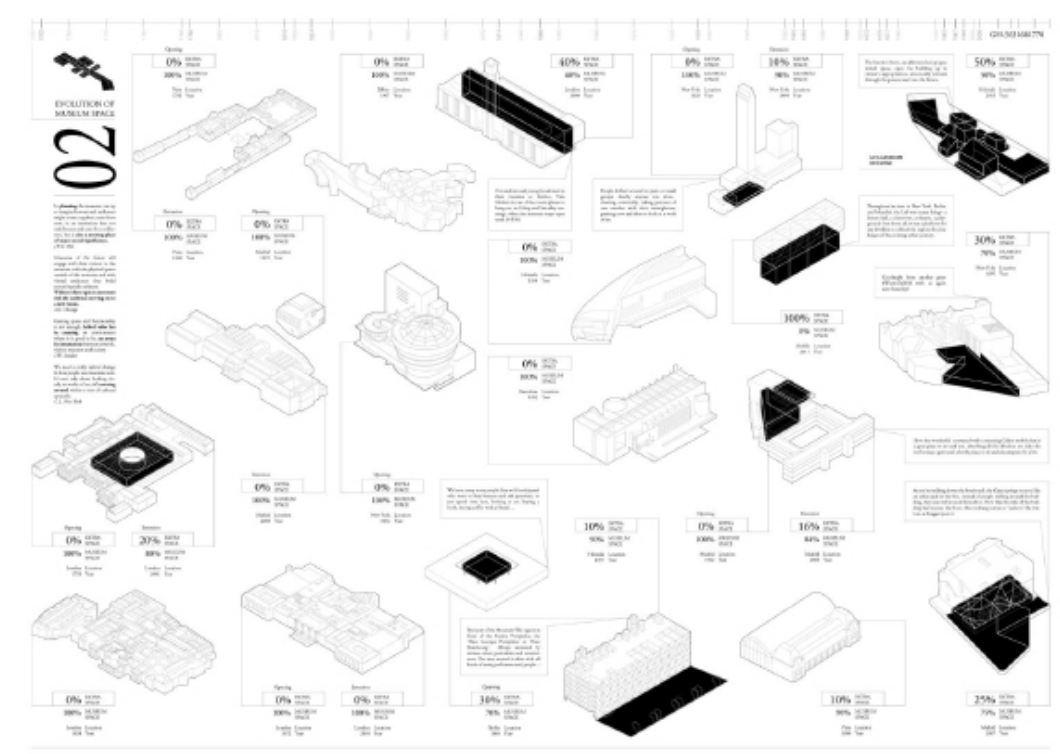

Fonte: concursosdeprojeto.org. Disponível em: http://www.concursosdeprojeto.org/2014/12/06/finalistas-museu-guggenheim

Figura 13 - Concurso - Museu Guggenheim Helsinki. Projeto Finalista: "Guggenheim Commons". Prancha 03.

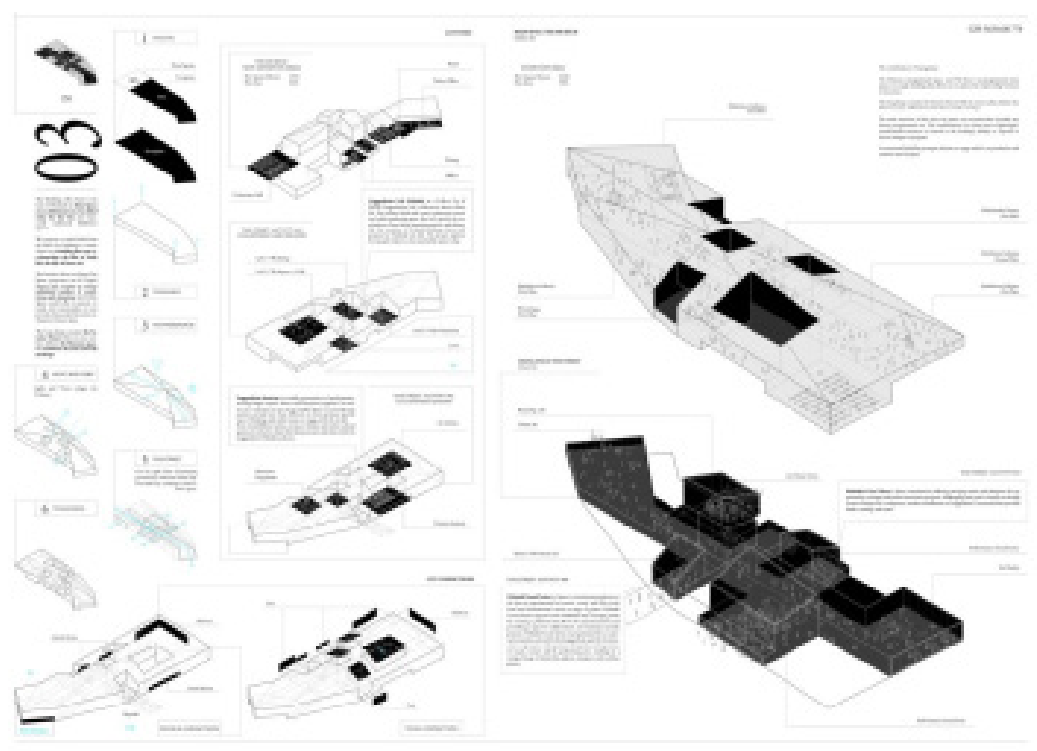

Fonte: concursosdeprojeto.org. Disponível em: http://www.concursosdeprojeto.org/2014/12/06/finalistas-museu-guggenheim

\section{Helsinki Five}

O conjunto vertical de torres revestidas em madeira e o circuito potencial de galerias proporcionado pelo átrio interno são os principais elementos destacados pelo Júri nesta proposta, apesar de alguns questionamentos sobre as soluções de circulação (como o uso excessivo de elevadores).

O uso de diagramas também é identificado neste projeto, porém de forma mais convencional. Na prancha 01 (figura 14) são utilizados diagramas conceituais relacionados ao contexto urbano e à iluminação.
A prancha 2 (figura 15) apresenta uma sobreposição de diagramas que buscam explicar o fluxo de visitantes às áreas de exposição, em solução que se assemelha ao Guggenheim de Nova Iorque, em que o visitante é conduzido ao topo do edifício e depois segue descendo os níveis à medida em que visita as galerias. A diferença está na solução da circulação, exemplar no caso do projeto de Frank Lloyd Wright em Nova lorque. Na quarta prancha (figura 16) são inseridos diagramas mais técnicos, dedicados ao conceito estrutural e à sustentabilidade. 
Figura 14 - Concurso - Museu Guggenheim Helsinki. Projeto Finalista: "Helsinki Flve”. Prancha 01.

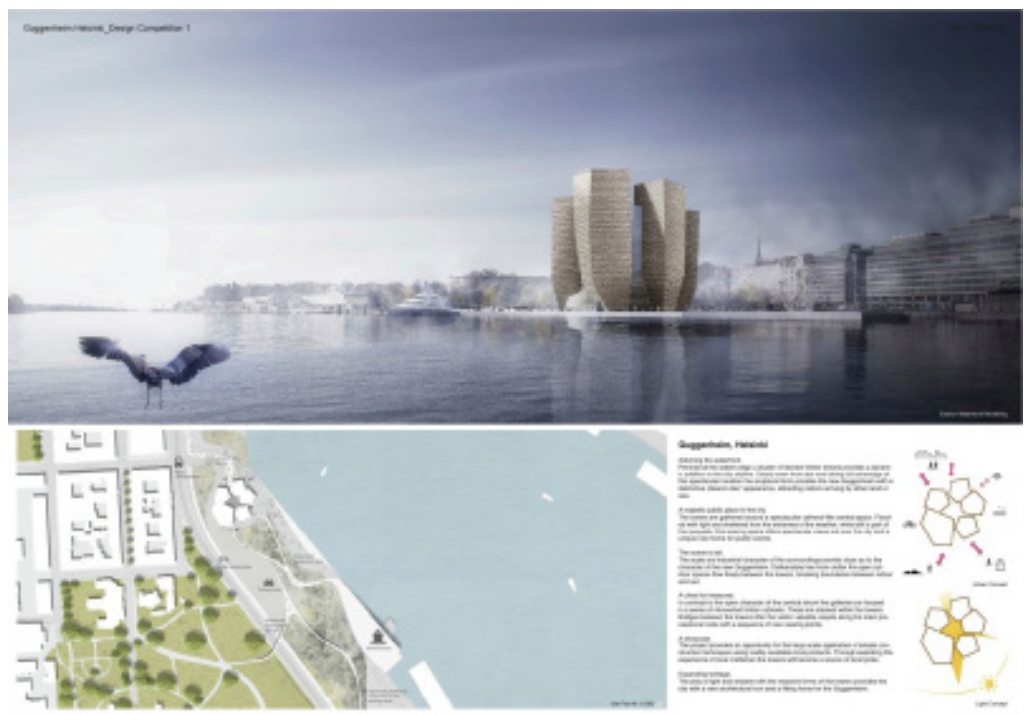

Fonte: concursosdeprojeto.org. Disponível em: http://www.concursosdeprojeto.org/2014/12/06/finalistas-museu-guggenheim

Figura 15 - Concurso - Museu Guggenheim Helsinki. Projeto Finalista: “Helsinki Five”. Prancha 02.
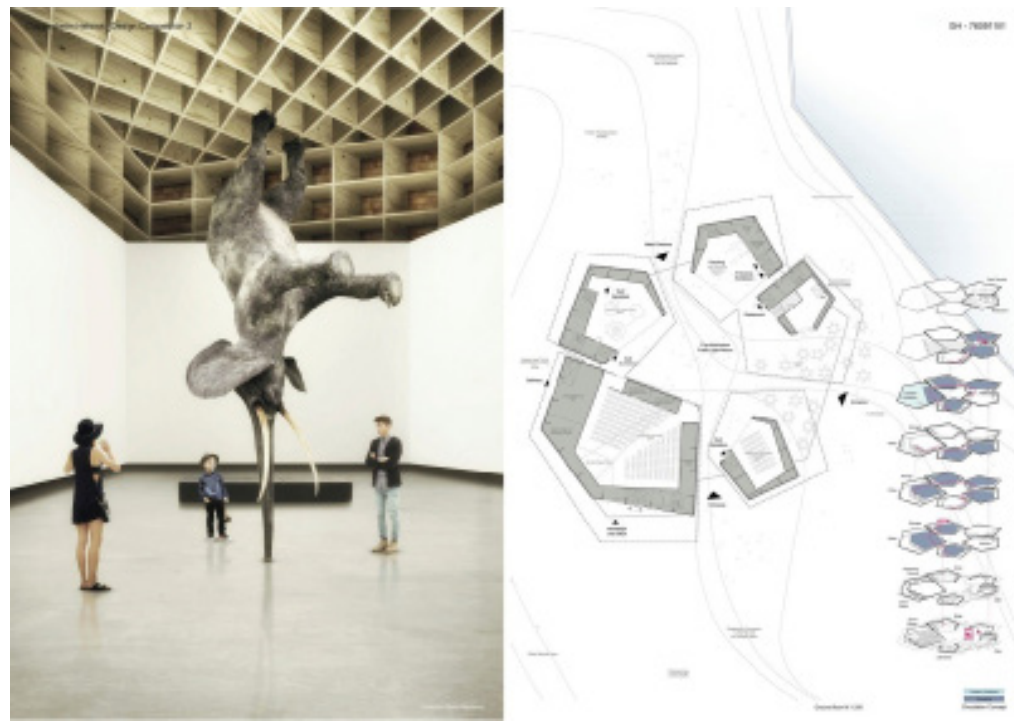

Fonte: concursosdeprojeto.org. Disponível em: http://www.concursosdeprojeto.org/2014/12/06/finalistas-museu-guggenheim

Figura 16 - Concurso - Museu Guggenheim Helsinki. Projeto Finalista: "Helsinki Five”. Prancha 04.
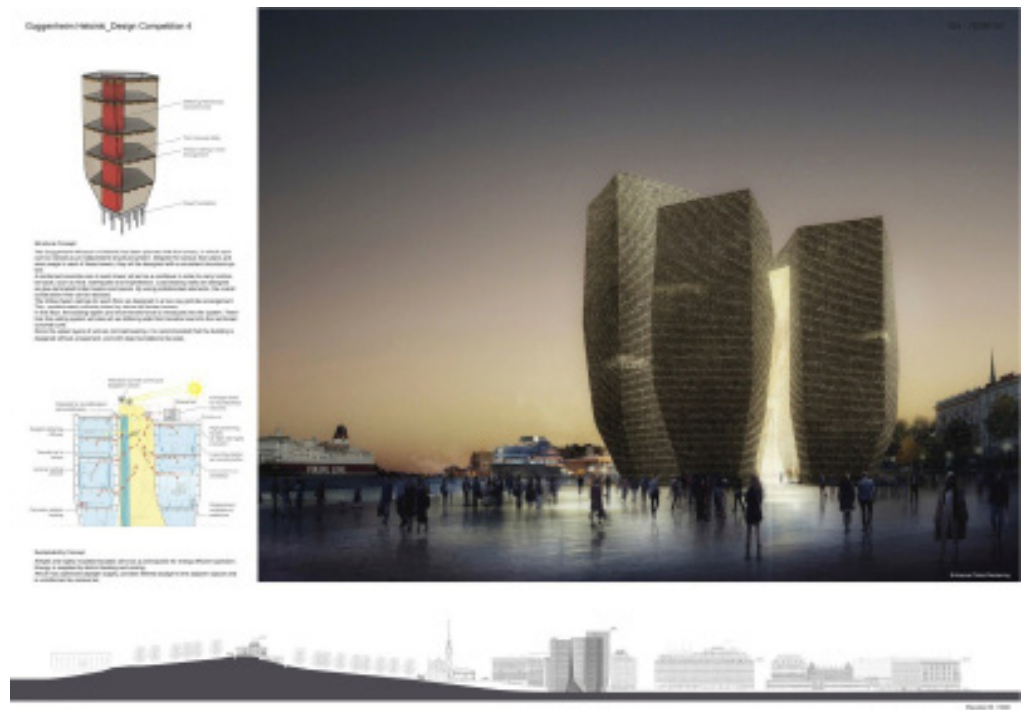

Fonte: concursosdeprojeto.org. Disponível em: http://www.concursosdeprojeto.org/2014/12/06/finalistas-museu-guggenheim 


\section{ESTRATÉGIAS DE COMPOSIÇÃO DIAGRAMAS ANALÍTICOS}

Conforme sugere Martinez (2000), a noção de composição implica: "colocar junto a, relacionar partes para formar um todo, decidir qual será a relação entre essas partes, criar uma estruturação do futuro edifício". Não se trata, como alerta o autor, de dar uma forma precisa e definitiva a um projeto, mas de apresentar especulações sobre a disposição geral e relativa dos espaços. Mais do que um produto, a composição é um processo projetual e são várias as estratégias identificadas por Martinez. A partir da leitura crítica de tais estratégias, propomos uma síntese analítica que se resume nas seguintes abordagens: (1) processo de composição e (2) produto da composição.

As possibilidades de articulação de forma, espaço e materialidade no processo projetual são aqui denominadas estratégias de composição. Martinez as define como modalidades operativas no ato de projetar que nem sempre serão usadas de modo consciente por parte dos projetistas. As estratégias compositivas atuam como processos eficazes que auxiliam na idealização do partido. Por não estarem evidentes em alguns casos, a análise das estratégias de composição nos permite trabalhar com interpretações hipotéticas de processos projetuais. Sob o ponto de vista processual sintetizamos o exercício de composição nos seguintes grupos:

a) Composição por Adição;

b) Composição por Subtração;

c) Composição Híbrida (ações complementares de adição, subtração e outros recursos complementares: deslocamento, rotação, torção, etc).

No que se refere ao conjunto resultante, identificamos os seguintes grupos:
a) Conjunto compacto;
b) Conjunto fragmentado;
c) Combinação entre fragmentação e compactação

Na arquitetura contemporânea, que é o foco desta pesquisa, Martinez argumenta que podem ser identificados tanto processos de composição aditiva quanto subtrativa e muitas das estratégias resultam dessa combinação: processo subtrativo para as partes e aditivo para o todo.
A partir das classificações referenciadas observamos um importante elemento de composição, comum às diversas estratégias: o vazio. As composições de projeto não se limitam à articulação entre volumes e espaços construídos, mas se referem principalmente à relação desses com os vazios (sejam internos ou circundantes, horizontais ou verticais).

Ao analisar os projetos finalistas do Concurso Internacional para o Museu Guggenheim de Helsinki, observamos uma diversidade de estratégias de composição espacial e volumétrica, em grande parte associadas a relações urbanas, funcionais e conceituais e muitas vezes explicitadas por meio de recursos gráficos diagramáticos. A fim de concentrar as análises sobre a composição e evitar distrações decorrentes do apelo visual das imagens de cada proposta, utilizamos o recurso do diagrama sintético analítico: para cada projeto foi elaborado um diagrama volumétrico com o mesmo padrão gráfico e elaborada uma matriz analítica, a fim de permitir a análise comparativa (Figura 17).

Figura 17 - Matriz Analítica - Diagramas - Finalistas do Concurso Internacional para o Museu Guggenheim Helsinki.

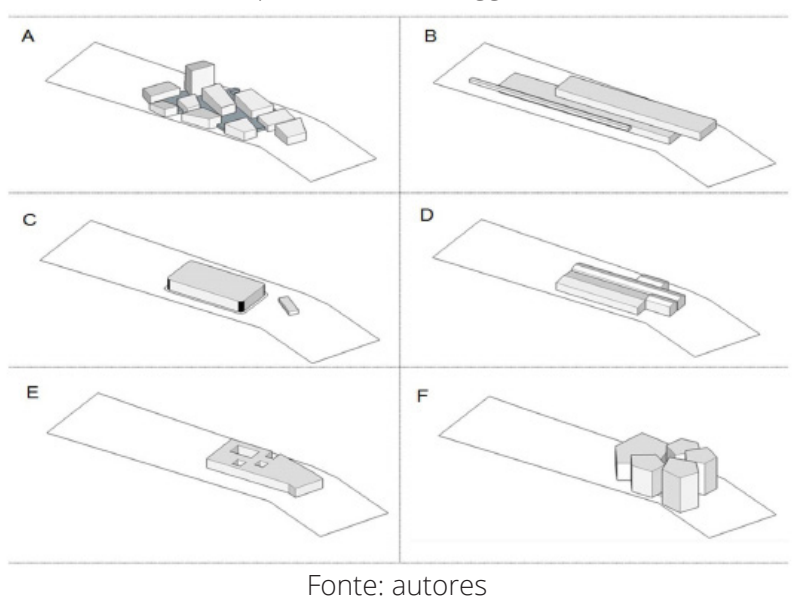

No que se refere à compacidade ou fragmentação, observa-se que a proposta intitulada "Art in the City" (Figura 15A) apresentou composição mais fragmentada e horizontal (exceto um dos volumes, mais verticalizado, utilizado como mirante), tanto dos volumes quanto dos espaços vazios, resultante da adição de volumes irregulares conectados por um conjunto de espaços também irregulares. Tal estratégia está na essência do conceito defendido pelos autores, de utilização dos espaços vazios entre os diversos pavilhões como elementos de articulação entre a cidade e o Museu.

O projeto "Two-in-one Museum" (Figura 15B) é bastante compacto e não se utiliza de vazios 
expressivos em sua composição. Trata-se de uma estratégia de composição por adição e sobreposição com leves deslocamentos horizontais, em que cada volume corresponde a uma das funções propostas e que definem o título do projeto: os espaços de convivência (térreo) e os espaços expositivos (pavimento superior).

O projeto "Quiet Animal" (Figura 15C) é um dos menos expressivos no que se refere à composição espacial e volumétrica, porém um dos mais originais em relação à envoltória. Tratase de um prisma, coberto por uma "pele", como uma membrana de proteção e de transição entre o espaço externo e o interno.

"47 Rooms" (Figura 15D) resulta de composição horizontal por adição de volumes simples e lineares e não se utiliza de vazios ou pátios. Não há expressividade volumétrica do conjunto, que conceitualmente faz referência aos galpões de armazenamento do porto.

"Guggenheim Commons" (Figura 15E) estabelece certa dualidade no que se refere à composição: volumetricamente (visto de fora) o volume expressa compacidade, porém internamente os espaços são fragmentados, em decorrência dos pátios e espaços livres criados, elementos essenciais na conceituação do projeto. Este projeto foi um dos que mais enfatizou o discurso urbano, aspecto expresso claramente nos diagramas, como vimos anteriormente.

A proposta intitulada "Helsinki Five" (Figura 15F) opta pela fragmentação de volumes irregulares e o espaço vazio como articulador do conjunto, porém mantém um único espaço vazio, centralizado. O que o diferencia em relação à composição volumétrica dos demais projetos é a sua verticalidade: as galerias são dispostas ao longo de pavimentos, gerando as cinco "torres de madeira" mencionadas pelos autores como elementos essenciais do conceito arquitetônico.

O julgamento final da segunda etapa do concurso ocorreu durante 3 dias, em maio de 2015. Nesta fase o Júri recebeu relatório analítico de uma comissão técnica sobre os aspectos técnicos, operacionais e de custo, sobre cada proposta finalista. Os projetos foram apresentados em nível mais detalhado ( 8 pranchas $A 1$, maquete detalhada - 1:200 e maquete para contextualização urbana - 1:500, além de memorial descritivo).
Os critérios de análise foram divididos em dois grupos: Essenciais (Contexto Urbano, Arquitetura e Funcionalidade) e Técnicos (Sustentabilidade e Viabilidade Técnica e Construtiva). A proposta "Art in the City" (Moreau Kusunoki Architectes, Paris) foi anunciada como vencedora e o segundo lugar foi atribuído a "Two-in-one Museum" (agps architecture, Zurique).

De acordo com o Júri, o projeto vencedor (Art in the (ity) se destaca pela cuidadosa inserção urbana, pela proposta fragmentada, nãohierárquica e horizontal e pela "rua coberta" criada pela combinação de pavilhões e espaços de transição, ora mais abertos ou mais fechados, conforme a relação com os ambientes e atividades circundantes. A proposta, ainda segundo a Comissão Julgadora, se destaca pela integração entre Arte e Sociedade e pela experiência expositiva gerada pela continuidade entre pavilhões, além do diálogo com os elementos do entorno: mar, parque e cidade. Destacou-se ainda o mérito de se apresentar como projeto contemporâneo, sem necessariamente ser icônico. O relatório do Júri ainda ressaltou a qualidade dos desenhos, que expressaram o sentido de comunidade e dinâmica social, importantes para a população local.

Em relação ao segundo lugar (Two-in-one Museum), o Júri destacou a força conceitual e o diálogo entre o antigo e o novo, em que forma, orientação e escala do conjunto proposto se encaixam com equilíbrio no contexto industrial e portuário. Algumas limitações referentes a circulação e conexões verticais foram mencionadas. Ainda de acordo com a Comissão Julgadora os espaços internos propostos são generosos (apesar das imagens não comunicarem bem tais qualidades).

\section{DIAGRAMAS ARQUITETÔNICOS OU ARQUITETURA DIAGRAMÁTICA ?}

A leitura e a análise de projetos contemporâneos sob a perspectiva da expressão diagramática nos oferecem uma série de reflexões e inquietações, entre as quais destacamos: qual o limite entre a produção de diagramas arquitetônicos e a promoção de uma arquitetura diagramática?

O diagrama arquitetônico, como vimos, é a expressão sintética, gráfica e textual, que tem como objetivo colaborar para a concepção e a composição arquitetônica. Em alguns casos a retórica apenas confirma ou evidencia estratégias de composição 
(espacial e volumétrica) desenvolvidas ao longo do processo de concepção e desenvolvimento: percebe-se, nesses casos, um equilíbrio entre o que foi projetado e o que está sendo comunicado. Em outros casos, a retórica é fabricada a posteriori, como um recurso de comunicação, não necessariamente vinculado ao exercício de projeto. Neste grupo incluímos as tentativas retóricas de agregar conteúdo e apelo visual a projetos que não nasceram de reflexões diagramáticas.

Identificamos ainda um terceiro grupo, que aqui denominamos "arquitetura retórica-diagramática". Neste grupo a postura sintética e retórica do diagrama condiciona o exercício projetual, em uma abordagem mais tipológica e menos topológica de tal recurso gráfico, isto é, mais associada à forma do objeto e menos à relação espacial entre seus componentes e destes com o contexto. Como consequência, na "arquitetura retórica-diagramática" o projeto passa a ser uma reprodução tipológica de exercícios de síntese gráfica superficial. O risco, neste caso, é a extrema simplificação do "fazer arquitetônico", reduzindo a complexidade do contexto e dos condicionantes a um conjunto de informações sintéticas, resultando em resposta arquitetônica superficial, cuja exequibilidade e aplicabilidade podem ser questionáveis. Tal processo pode ser associado diretamente a críticas recentes sobre a massificação da informação por meio da internet, que também tem afetado a Arquitetura: um conteúdo cada vez maior, assimilado de forma cada vez mais rápida, porém quase sempre superficial. Trata-se, conforme sugerem Sperling e Rosado (2014) de uma arquitetura midiática, diretamente relacionada ao que alguns críticos classificam como "TEDificação" do conhecimento (SADLER, 2014). Nessa perspectiva, não é exagero afirmar que tem ocorrido uma simplificação extrema dos problemas arquitetônicos por meio de sínteses visuais. Quando tal exercício de síntese gráfica não é acompanhado da necessária reflexão e do recomendável aprofundamento, o resultado é o diagrama como fim e não como meio, reduzindo a complexidade inerente dos problemas arquitetônicos e urbanos a retóricas frágeis e superficiais. Segundo Montaner (2014), os diagramas na Arquitetura ajudam a comunicar ideias, mas também podem se converter em instrumentos de simplificação extrema da realidade, que empobrecem o projeto, convertendose em mera retórica:

\begin{abstract}
Os diagramas são úteis para projetar o futuro, para responder a novos impulsos sociais, culturais, energéticos e ambientais. Tempos de mudança demandam instrumentos de projeto abertos e versáteis (...). O diagrama é ativo, uma ferramenta de novidade. É necessário para que se possam superar os hábitos, clichés e estereótipos, para que se possam experimentar novas referências. Por outro lado, deve-se evitar que os diagramas se convertam em sistemas arbitrários, sem referências, excessivamente abertos, autônomos e abstratos." (Montaner, 2014, p.12)
\end{abstract}

Os projetos finalistas para o Museu Guggenheim de Helsinki, no que se refere à forma de utilização de estratégias diagramáticas, apresentam um rico repertório de recursos gráficos, com a utilização de elementos visuais e textuais que vão além do conceito tradicional de diagrama, e que de maneira geral conseguem equilibrar síntese e profundidade conceitual. Em boa parte desses projetos as estratégias diagramáticas (tanto as mais abstratas quanto as mais técnicas) parecem bem vinculadas aos conceitos propostos, assim como ao contexto de implantação do projeto. Muitas das qualidades destacadas pelo júri, como vimos, coincidem com discursos apresentados de forma diagramática pelos autores. O que percebemos, enfim, entre os finalistas do Concurso para o Guggenheim de Helsinki, com toda sua diversidade de abordagens, são diagramas arquitetônicos utilizados como síntese conceitual, e não uma "arquitetura retórica e diagramática", que se resume ao apelo midiático.

\section{REFERÊNCIAS}

ADAMCZYK, G. Final Cut - A Remarkable Cross-Section of Architectural Tendencies. In: Architecture Competitions and the Production of Culture, Quality and Knowledge - An International Inquiry. Potential Architecture Books. 2015

BOUTINET, J. Anthropologie du projet. Paris: Presses Universitaires de France, 1990.

CHUPIN, J. et al. A World of Potentialities - Competitions as Producers of Culture, Quality and Knowledge. In: Architecture Competitions and the Production of Culture, Quality and Knowledge - An International Inquiry. Potential Architecture Books. 2015.

CHUPIN, J.; BILODEAU, D.; ADAMCZYK, G. Reflective knowledge and potential Architecture. In: L. Fontein; M. Bressani; S. Hanrot (Orgs.); ARCC/AEEA Conference on Architectural Research. Anais... . McGill University School of Architecture, 2002.

GALOFARO, L. Digital Eisenman: An office of the electronic era. Birkhauser, Basel. 1999.

IZAR, G. Diagramática: Descrição e Criação das Formas na Arquitetura Seriada de Peter Eisenmam. Tese de Doutorado. FAU-USP. Paulo, 2015. 
GARCIA, M. The Diagrams of Architecture. AD Reader, 2010.

MALCOLM READING CONSULTANTS. Guggenheim Helsinki Design Competition. Disponível em: http://designguggenheimhelsinki.org/ en/about/

MARTINEZ, A. Ensaio sobre o projeto. Editora Universidade de Brasília. 2000.

MONEO, R. Inquietação teórica e estratégia projetual na obra de oito arquitetos contemporâneos. Cosac Naify. São Paulo, 2008.

MONTANER, J. A modernidade superada. Ensaios sobre arquitetura contemporânea. GG Brasil. 2014.

MONTANER, J. Del diagrama a las experiencias, hacia una arquitectura de la acción. GG Editora. Barcelona, 2014.

SADLER, S. TEDification versus Edification. 2014. Recuperado de: https://placesjournal.org/article/tedification-versus-edification/

SPERLING, D. e ROSADO, C. Diagrama: entre projeto e comunicação - o caso BIG. SIGRADI 2014. XVIII Congreso de la Sociedad Iberoamericana de Grafica Digital. Blucher Design Proceedings. Volume1, Número 8. Dezembro, 2014.

SOBREIRA, F. Design Competitions in Brazil - Building a [Digital] Culture for Architectural Quality. In: Architecture Competitions and the Production of Culture, Quality and Knowledge - An International Inquiry. Potential Architecture Books. 2015.

STEELE, B. (org). Supercrítico. Cosac Naify, 2013.

TOSTRUP, E. Architecture and Rhetoric: Text and Design in Architectural Competitions, Oslo 1939-1996. Papadakis Publisher. 1999.

\section{NOTAS}

(1) Este artigo é resultado de pesquisa de iniciação científica realizada no Curso de Arquitetura e Urbanismo do UniCEUB, sob a coordenação do Prof. Fabiano Sobreira, com a participação das estudantes-pesquisadoras Amanda Siebel e Adriana Guimarães.

NOTA DO EDITOR (*) O conteúdo do artigo e as imagens nele publicadas são de responsabilidade do(s) autor(es). 